\title{
Exploring Work Environment Usage Behaviour through Context-Aware Mobile Methods
}

\author{
Piia Markkanen ${ }^{1}$, Niels van Berkel ${ }^{2}$, Aku Visuri $^{3}$, Arthur LeSaint $^{4}$, \\ Denzil Ferreira ${ }^{5}$, Aulikki Herneoja ${ }^{6}$ \\ ${ }^{1,6}$ Oulu School of Architecture, University of Oulu ${ }^{2}$ University College London \\ ${ }^{3,4,5}$ Faculty of Information Technology and Electrical Engineering, University of \\ Oulu \\ 1,3,5,6\{piia.markkanen|aku.visuri|denzil.ferreira|aulikki.herneoja\}@oulu. \\ fi²n.vanberkel@ucl.ac.uk
}

This paper presents our findings on knowledge work environment usage behaviour through a combined automated mobile indoor positioning system and self-reports collected from the environment's inhabitants. Contemporary work environments are increasingly flexible multi-occupant environments as opposed to cellular offices. Understanding persons' task-related and situation-related environmental needs is critical to improve the design of future knowledge work environments. This study is conducted in a team office environment prior to and following an intervention in which the office layout was re-organized. The combined methodological approach described in this paper provides a new tool for architecture researchers aiming to understand the use of workspaces. Importantly, combining self-reports with context-aware location data collection provides researchers an efficient in situ tool to access participants experiences and decision-making process in choosing their workstation or workspace.

Keywords: knowledge work environment, team office, activity-based work environment, experience sampling method, research-by-design

\section{INTRODUCTION}

Contemporary knowledge work environments have evolved to respond to the new ways of working and to communication and collaboration in knowledge creation (De Croon et al. 2015, Wohlers and Hertel, 2017). Activity-based working is occurs within a variety of workspaces designed to accommodate different tasks. Importantly, in such environments, employees have the option to choose the workstation that best supports the task and their personal preferences (Appel-Meulenbroek et al 2011). Offices with assigned workstations are called multi-space offices (Boutellier et al. 2008) and with flexible seating are activity-based offices (Appel-Meulenbroek et al. 2011), flex-offices (Bodin Danielsson et al. 2014), or activity-based flexible office (Wohlers and Hertel, 2017).

Collaborative working affects the sensed level of privacy, distraction-free working, and perceived productivity in multi-tenant workspaces (Heerwagen et 
al. 2004). Activity-based work environments contain different spaces suitable for concentration intensive work, private work, and collaborative work. In such environments, employees are able to choose their work location suitable for their tasks and personal preferences. Interestingly, individuals' own behavior appears to play an important role in the users' satisfaction towards their work environment: individuals who actively switch their workstations and workspace have been shown to demonstrate higher satisfaction towards their work environment opposed to individuals with low switching activity (Hoendervanger et al. 2016). Person-Environment fit theory has been lately applied to knowledge work environment research as Need-Supply fit (Gerdenitsch et al. 2019) or Job-Environment fit (Hoendervanger et al. 2018) in the context of activity-based flexible work environments. Finding the optimal fit may be dependent on person's psychological needs, job characteristics, but also on workspace availability, functionality, comfort, and aesthetic quality (Gerdenitsch et al. 2018, Hoendervanger et al. 2018). Understanding persons' task-related and situation-related environmental needs is important to improve the future design of knowledge work environments.

Although current research often focuses on activity-based flexible work environments, in this study our focus is a team office. Team offices are small open-plan offices with 4-9 persons sharing the same space (Duffy 1997, Bodin Danielsson \& Bodin 2008). In this paper, we present our findings how participants of this study use their work environment using a methodology that combines indoor positioning system with experience sampling method (ESM). Our study indicates how users have different behavioural patterns in terms of switching their location, but importantly, how the same work space is used for tasks requiring different levels of communication and privacy.

\section{METHODS OF RESEARCH}

This research was implemented in a real-world environment as part of a knowledge work environment research project described in (Markkanen and Herneoja 2018) and (Markkanen et al. 2017). The participants of the research were the founders $(n=3)$ and the employees $(n=7)$ of a small-scale ICT-company. The company was located in a two-room office of altogether $65 \mathrm{~m}^{2}$ with additional facilities available for shared use with other companies, such as meeting room and break room.

\section{Intervention and implemented changes in layout}

The research followed a four-phase process: preanalysis - design - intervention - evaluation (Markkanen and Herneoja, 2018). Altogether, implemented changes consisted of spatial layout of the office, lighting, acoustic elements and collaboration supporting elements. During the pre-analysis phase of the study, the participants of the study were invited to semistructured interviews $(n=5)$ and a participatory design workshop ( $n=3$ ) to elucidate the user-needs, daily situations and work tasks. We identified individual, group, client-related tasks, and recovery, as participants' daily habits. The intervention was designed to increase collaboration between co-workers (especially Room 1), to increase privacy through acoustic screens (Room 2), to provide an Informal meeting area with collaborative knowledge creation supporting elements, and to support privacy of phone and Skype meetings with a phone booth. The implemented changes in layout are presented in figure 1.

\section{Location data gathering methods}

Smartphones have quickly become commodity devices, used frequently throughout the day by an overwhelming portion of the population. These devices come equipped with a wide range of sensors, and are typically carried by their owner throughout the day. This combination makes them an excellent instrument for scientific inquiry (Raento et al. 2009). By activating smartphone sensors, contextual information on the participants activity (e.g., whereabouts, smartphone usage, etc.) can be automatically and continuously collected.

Although smartphone sensor data can tell us a 
Figure 1

The study was

completed prior

and during

intervention. The

office layout and

workstation

arrangement was

re-designed for the

intervention (see

Markkanen and

Herneoja, 2018, for

more information).

The bottom

diagram presents

the location of

participants'

assigned

workstations,

Bluetooth beacons,

and location of

Room 1, Room 2

and Informal

meeting area.

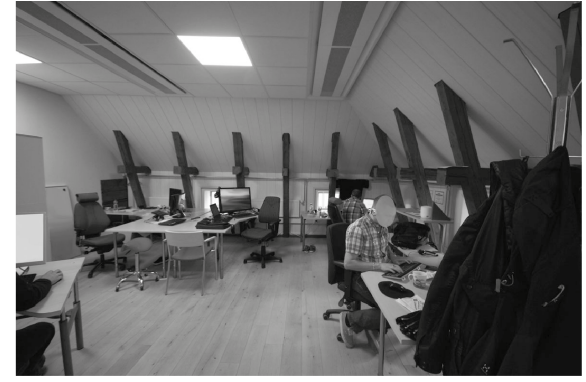

PRE-INTERVENTION

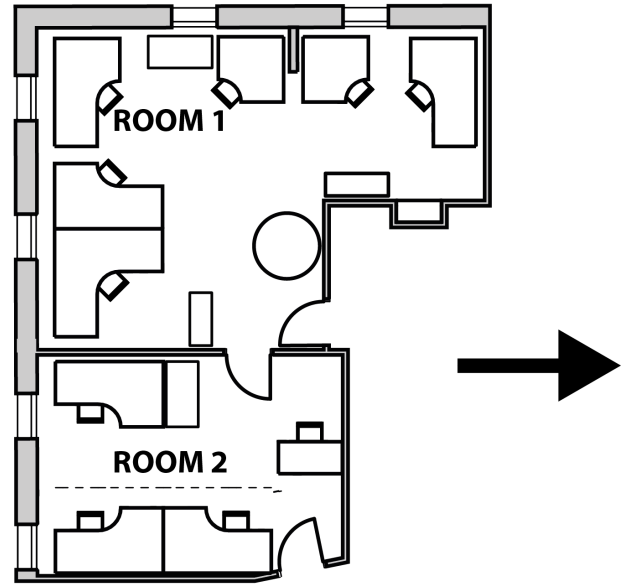

Location of bluetooth beacons and participants

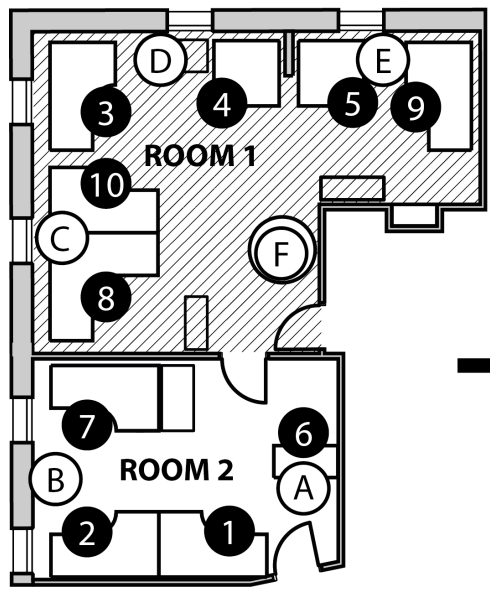

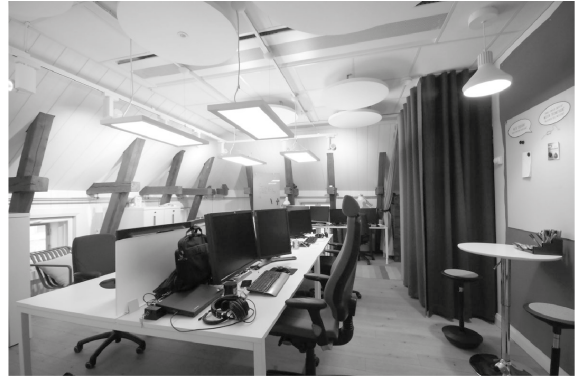

INTERVENTION

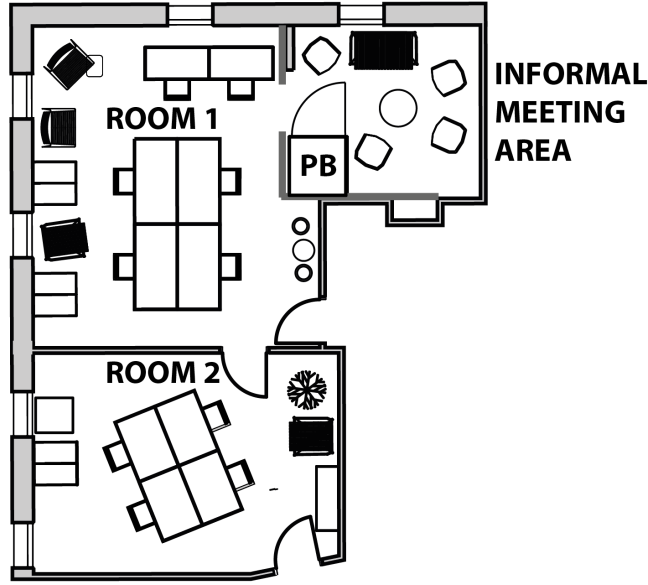

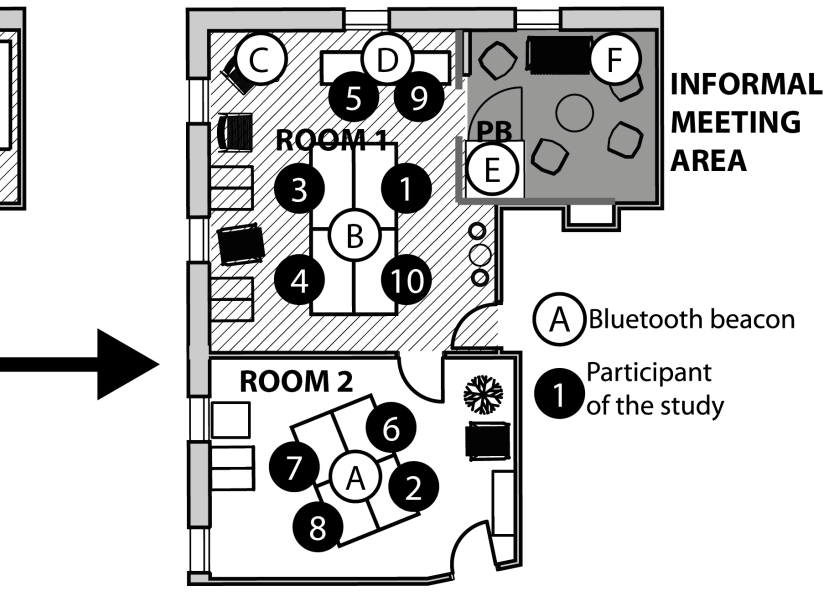

Challenges - BIG DATA AND ANALYTICS - Volume 2 - eCAADe 37 / SIGraDi 23 | 839 
lot about the context of the device, and therefore the user of the device, researchers are likely interested in data beyond these sensor readings. The Experience Sampling Method (ESM) is a data-collection method in which study participants repeatedly answer a set of questions as they progress through their day-to-day activities. Although the ESM was originally applied for keeping track of activities (Larson et al. 1983), it is currently widely used for the collection of a variety of human experiences (van Berkel et al. 2018). As participants report on phenomena of interest as they live their regular life, collected responses have a high ecological validity as compared to a typical one-off survey completed in a stationary location. The combined use of automated sensor data collection and manual participant self-reports provides the opportunity for a rich and diverse data collection method - revealing insights, which cannot be achieved by either one data collection approach individually.

The study was performed in two phases: preintervention data was collected for 11 workdays (Monday to Friday, weekends were excluded) prior pilot intervention and for 20 days during pilot intervention. Participants of the study $(n=10)$ were provided with smartphones and they were asked to carry them while working in the office during the data collection periods. The smartphones were used to prompt and collect ESM reports and the location data. The ESM inquiry was built on AWARE platform, which is a mobile instrumentation toolkit. The sensor capabilities of smartphones were used to trigger the ESM inquiry. The requests to fill the inquiries were sent to participants when the AWARE sensed movement of the phone, thus indicating the participant changing location in the space and likely switching between tasks. This was to prevent the disturbance of research setting during different tasks for the participants. The ESM inquiry contained following steps: A) Select a situation (radio button), B) Select location (radio button), C) With whom? (checkbox), and D) Did the space support...? (various options: Concentration, Communication, Undisturbed working, Problem solving, Producing new knowledge or a product, Inno- vation, Presentation, Privacy, Did collaborative phasing support your work, 5-point likert scale), E) Duration (mins), F) Free comment (open field). The AWARE platform was used to collect the physical location of the participant in the office: 6 Bluetooth beacons were placed in the office to track the location of the smartphones to the nearest beacon. The locations of Bluetooth beacons and participants' assigned workstations are presented in figure 1 .

\section{RESULTS}

The location data and ESM reports were collected for 11 workdays prior intervention and 20 workdays during intervention. The data collection during intervention started on week 2 of intervention to let participants adjust to the change. Prior intervention, participants 3, 4, 5, 8, 9, and 10 were located in Room 1, and participants 1, 2, 6, and 7 in Room 2. Participant 1 and participant 8 switched their room when intervention started.

\section{Location data reveals switching behaviour between workspaces}

The participants' location data was collected through smartphone sensor data and Bluetooth beacons. Participants' raw signal quantity varied greatly depending on their smartphone movement, charging levels and participants' working hours during the data collection periods. The signals were analysed as percentages collected from Room 1 and Room 2 prior intervention and from Room 1, Room 2, and Informal meeting area during intervention. The data collection areas are presented in figure 1. The ratios of location signals prior and during intervention are presented in figure $2 \mathrm{~A}$. The shared facilities in the building, such as break room, toilets and meeting room were excluded from this study. 
Figure 2

A) The locations signals were analyzed from Room 1, Room 2, and Informal meeting area. B) Combined data of assigned room, adjacent room and Informal meeting area reveal decreased room switching behavior during intervention.

\section{A Room specific location signal}

\section{Participant}

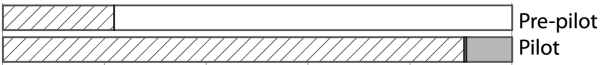

2

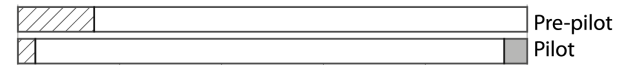

3

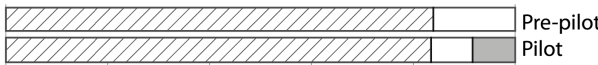

4

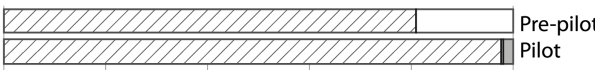

5

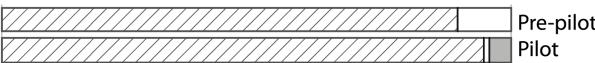

6

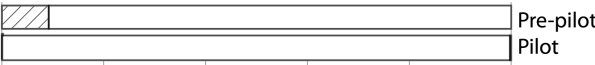

7

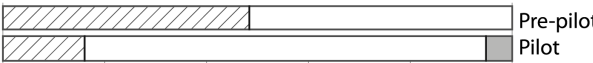

8

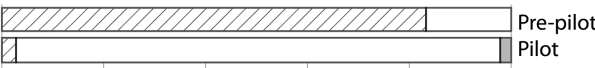

9

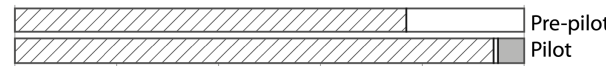

10

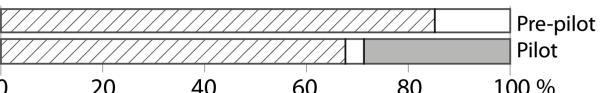

Pre-intervention $\square$ Room 1 Room 2 Informal Intervention $\quad \square$ Room $1 \square$ Room $2 \square$ meeting area

B Workspace switching activity

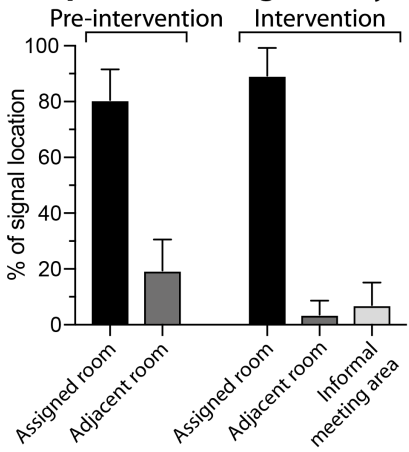

Prior intervention $81 \pm 11 \%$ (mean \pm S.D.) signals were collected from the room in which the participants' assigned workstation was located (figure $2 \mathrm{~B}$, Assigned room) and $19 \pm 11 \%$ from the adjacent room. In this paper, we consider the presence in adjacent room and in the Informal meeting area as switching activity. This ratio changed during intervention in a manner that indicated decreased room switching behaviour with $89 \pm 9.9 \%$ Assigned room signal and $3.7 \pm 5 \%$ Adjacent room signal. Furthermore, data showed $7.0 \pm 8.1 \%$ signal from Informal meeting area. There were differences between the participants, indicating more frequent switching behaviour for some participants.

The location data was also visualized through a webpage that shows historical location data from all of the 10 devices carried by the participants of the study. The data is visualized on the layout of the office (see figure 3 ). The collected dataset contains timestamp and the signal strength - measured by the smartphone carried by each participant - to all the Bluetooth beacons in the office (or the ones the smartphone can observe). The signal strength is then used to measure an approximation of each smartphones' location in the office space. Furthermore, as each participant has a designated desk, the location of a smartphone is fixed on their own work area in cases where their current location contains their own work area.

The data collection is continuous, but still happens only at a certain interval. Thus, we divided the location information into segments of different duration (e.g., one minute, five minutes, etc.) and each data entry within the time window was used to showcase different locations visited by the individual during this time window. The map location is an approximation based on the nearest sensor and pinpoints the nearest work desk, or other focus location of the office (such as the Informal meeting area). If several individuals are in the same area of the office, the visualisation automatically clusters the users around the center point of that location.

The visualized location data was used to observe 
A

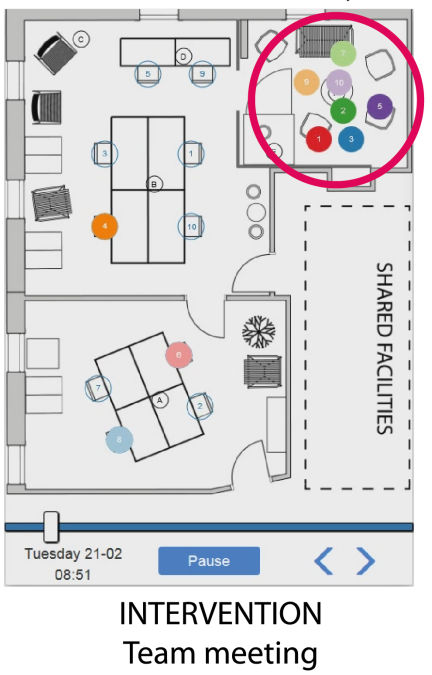

B

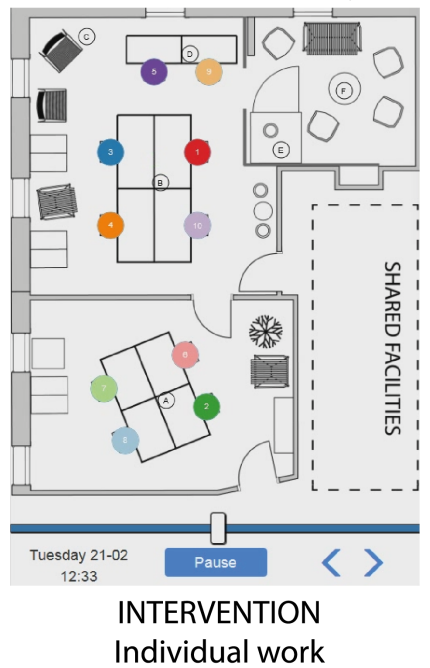

C

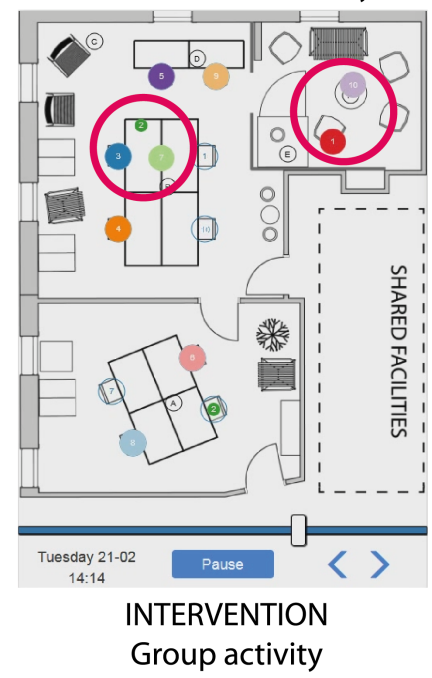

Figure 3

The location data

was processed into

a visual format

depicting the

location of each

participant. This

data was used to

verify events, such

as team meetings

(A and $B$, red

circles), individual

work (C), and

different group activities $(D$, red circles).

behavioural patterns indicating group activities. Preanalysis phase of the study informed that participants gather daily for morning meetings. We were able to positively identify these team meetings on 10 out of 11 mornings prior intervention and on 16 out of 20 mornings during intervention from visualized grouping of the participants' signal symbols, as depicted in Figure $4 \mathrm{~A}$. The location of these meetings occurred in Room 1 prior intervention $(n=10)$ and during intervention in the Informal meeting area $(n=13)$, or alternatively in the Room $1(n=2)$ or in the shared meeting room $(n=1)$. Visualized location data can also be used to distinguish possible collaborative events (See Figure 4 D), such as ad hoc problem solving.

\section{Experience sampling of tasks and activities}

The semi-structured interviews $(n=5)$ and workshop $(n=3)$ elucidated tasks and activities typical for the participants of this study. The tasks and activities were divided as follows: 1) Individual tasks, which vary depending on the job description of participants. These tasks consist of routine and non-routine tasks concerning software development, marketing, accounting and administrative tasks. 2) Group activities, which include ad hoc problem solving, problem solving with the team, team meetings and steering group work. Ad hoc problem solving situations typically occur as employees encounter problems while working that require prompt solving in order for the employee to continue with their work. Problem solving with a team can be a planned meeting of two or more participants where solutions are sought out together for a pre-determined problem. Team meetings are organized daily to share information amongst the whole team and Steering group meetings are organized amongst the owners of the company and require higher level of privacy. 3) Client communication is considered important in the company. The communication events occur either at the clients' office or in In-office meetings, through Phone meetings or Skype meetings. 4) Recovery is important part of a well-balanced workday and part of the social environment in the office. This includes events such as Lunch, coffee and other breaks. 
Figure 4

Participants reported 50 ESM events prior intervention $(A)$ and 212 ESM events during intervention (B). The location of the events are visualized in (C).

A Reported ESM events prior intervention ( $n=50$ ESM reports)

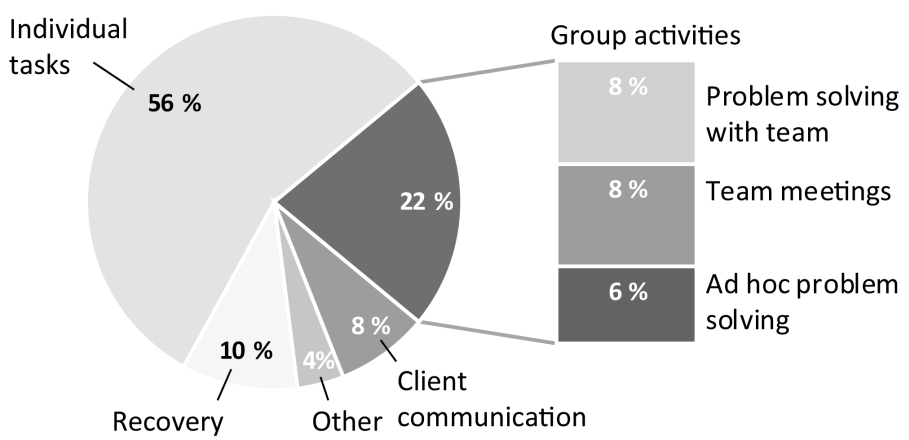

\section{B Reported ESM events during intervention ( $n=212$ ESM reports)}

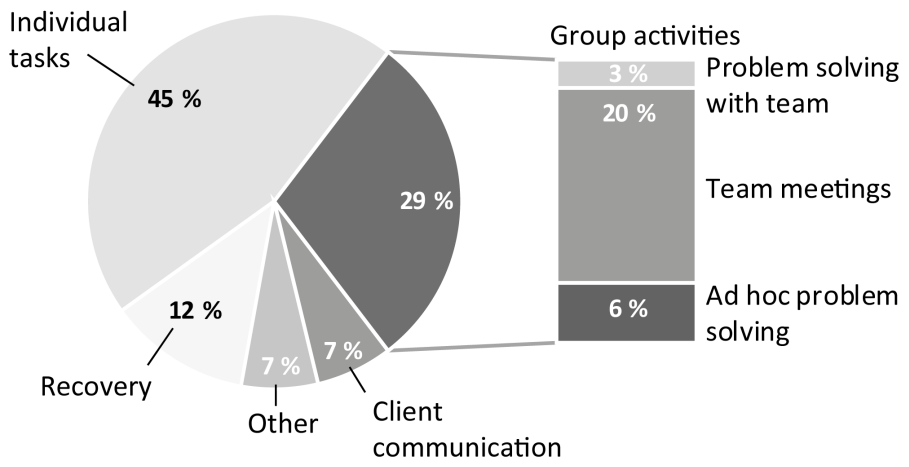

\section{Location of reported ESM events}

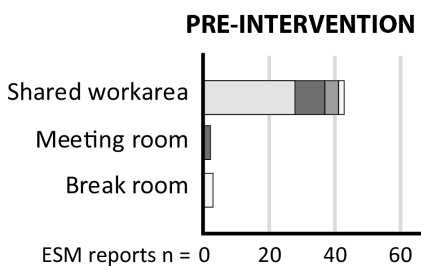

$\square$ Individual work

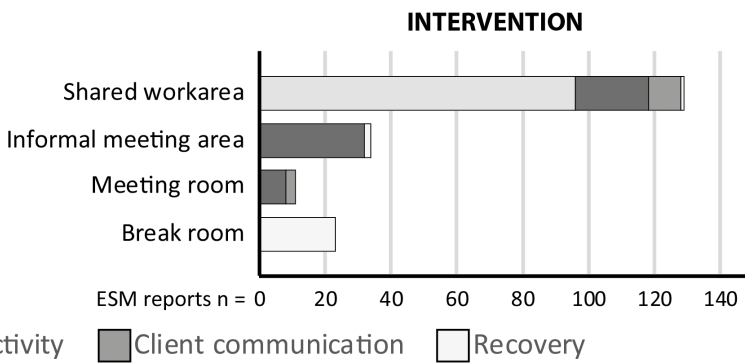


The ESM questionnaires collected information on daily events in the following order: task, location, involved participants, and participants' experience on how the workspace supported the reported event. Altogether, participants responded to $n=50$ pre-intervention and $n=212$ intervention ESM inquiries. The ratio of different tasks in ESM reports is similar prior and during the intervention. The most notable changes occur in percentage of reported individual working events (decreased from $56 \%$ to 45 $\%$ ) and group activity events (increased from $22 \%$ to $29 \%)$. Here, the number of team meetings increased from $8 \%$ to $20 \%$. From the analysis of location data, the team meetings occurred approximately 4 times a week, thus the increased number is not due to increased number of events. Rather, the number of team meeting events in ESM reports is likely due to more prompted ESM inquiries as all participants taking part of the team meeting moved from their assigned workstation into Informal meeting area.

\section{Individual tasks and group tasks occur in shared work area}

The second step in ESM inquiry concerned the location of the reported events. The list of locations differed prior and during intervention due to changes in the office layout. For the purpose of this analysis, the ESM reports were grouped into Shared work area (workstations and seating located in Rooms 1 and 2), Informal meeting area, Meeting room, and Breakroom. There were no reports from Phone Booth. The figure $4 \mathrm{C}$ presents the location of the Individual, Group, Client and Recovery events. This data reveals that major proportion of Group activities and Client communication events occur simultaneously in the same area where un-involved participants perform Individual work tasks. ESM reports revealed $\mathrm{n}=32$ group activity or client communication events from the shared work areas and $n=96$ individual work events during intervention. This indicates that while Room 1 and Room 2 are intended for individual concentration intense working, same workspace is used for collaborative working, which requires communication and may disturb individual work.

\section{Number of participants in the events}

The number of participants' in different events are presented in table 1. The highest number of participants were in team meetings. The ad hoc problem solving events were typically two person situations whereas problem solving with team ranged between 2 to 6 participants during intervention. Client communication event participant number varied from 1 to 10 , thus indicating that these events are versatile in nature.

\section{Experiences of task-environment support}

The following step in ESM inquiry assessed how the selected location supported reported event. The participants were asked Did the space support...? and given multiple options to evaluate on 5-point Likert scale $(0=$ not applicable, $1=$ strongly disagree, 5 = strongly agree). The options were Concentration, Communication, Undisturbed working, Problem solving, Producing new knowledge or a product, Innovation, Presentation, Privacy, Did collaborative phasing support your work?. Due to small dataset in this pilot study, we present here only the data from Individual tasks during intervention with $\mathrm{n}=96$ ESM reports. The figure 5 presents the scores from these ESM reports. Interestingly, participants reported their experienced support-level most often for Concentration (3.4 \pm 0.9$)$, Undisturbed working (3.0 \pm 0.9$)$, Problem solving ( $3.5 \pm 0.9)$, and Privacy $(2.5 \pm 1.1)$. This reflects the importance of these factors on their working while performing their Individual tasks. Although the dataset is small, participants reported more positive scores for Concentration and Problem solving whereas they reported more negative scores Undisturbed working and Privacy. 
Table 1

The number of participants in ESM reported events prior and during intervention.

Figure 5

The ESM inquiry contained section where participants were asked "Did the space support...?" different qualities of work environment. The figure shows the results of reported ESM events of individual work during intervention.

\begin{tabular}{|c|c|c|c|c|c|c|c|}
\hline \multicolumn{8}{|c|}{ Pre-intervention - number of participants during events } \\
\hline & $\begin{array}{l}\text { Individual } \\
\text { tasks }\end{array}$ & $\begin{array}{c}\text { Problem } \\
\text { solving with } \\
\text { team }\end{array}$ & $\begin{array}{c}\text { Team } \\
\text { meetings }\end{array}$ & $\begin{array}{l}\text { Ad hoc } \\
\text { problem } \\
\text { solving }\end{array}$ & $\begin{array}{l}\text { Communi- } \\
\text { cation with } \\
\text { clients }\end{array}$ & Recovery & Other \\
\hline $\mathrm{n}$ & 28 & 4 & 4 & 3 & 4 & 5 & 2 \\
\hline Mean $\pm S D$ & $1,0 \pm 0$ & $1,8 \pm 0,50$ & $9,5 \pm 0.58$ & $1,7 \pm 0,58$ & $2,3 \pm 0,96$ & $3,8 \pm 2,7$ & $1,0 \pm 0$ \\
\hline Range & 1 & $1-2$ & $9-10$ & $1-2$ & $1-3$ & $1-7$ & 1 \\
\hline \multicolumn{8}{|c|}{ Intervention - number of participants during events } \\
\hline & $\begin{array}{c}\text { Individual } \\
\text { tasks }\end{array}$ & $\begin{array}{c}\text { Problem } \\
\text { solving with } \\
\text { team }\end{array}$ & $\begin{array}{c}\text { Team } \\
\text { meetings }\end{array}$ & $\begin{array}{l}\text { Ad hoc } \\
\text { problem } \\
\text { solving }\end{array}$ & $\begin{array}{l}\text { Communi- } \\
\text { cation with } \\
\text { clients }\end{array}$ & Recovery & Other \\
\hline $\mathrm{n}$ & 96 & 6 & 43 & 13 & 14 & 26 & 14 \\
\hline Mean \pm SD & $1,0 \pm 0,10$ & $2,8 \pm 1,6$ & $7,1 \pm 1,5$ & $1,9 \pm 0,28$ & $2,2 \pm 2,4$ & $3,8 \pm 1,9$ & $1,9 \pm 1,7$ \\
\hline
\end{tabular}

\section{Work environment support for individual work}

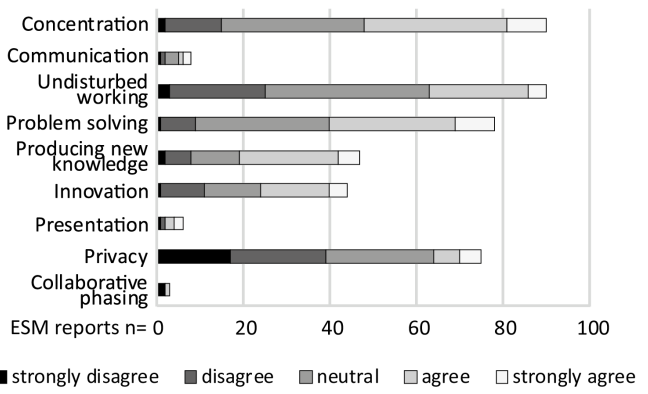

\section{DISCUSSION}

Employees' satisfaction towards their work environment is dependent on the extent to which the physical work environment meets the employees' needs (Van der Voordt 2004). However, trying to understand the users' satisfaction towards their environment is much more complex. For example, personal characteristics such as age, gender and personality affect satisfaction with work environment (Bodin-Danielsson and Bodin 2008, De Been and Beijer 2014, Hartog et al. 2018). Contemporary knowledge work environments provide their users different spaces and workstations that support range of tasks, concentration intensive working and various communication events. Optimally, in activity-based working environments, employees have a choice to find such workstation or work space that optimally supports their person-environment fit (Wohlers and Hertel, 2017, Gerdenitsch et al. 2018, Hoendervanger et al. 2018).

Work environment research classically uses questionnaires and interviews. Different location tracking studies have emerged and their methodology differ depending on the research question, location and needed accuracy. In this study, the combination of smartphones and Bluetooth beacons were used to test context-aware data collection that combined the location data and ESM in the context of work environments. Surprisingly, the ESM has not been often used in work environment research, even though the method enables participants to report their experiences as they occur, thus minimizing the memory bias. For example, Weijs-Perrée et al. (2018) used ESM to study face-to-face interaction events through online questionnaire for 60 min prior the prompt. In this study, we used ESM to collect information on various events as they occurred. The reports consisted of information of the task, the location, the participants, and evaluation of how the space supported, for example, concentration, communication, undisturbed working, and privacy. Although the dataset in this pilot study was limited, this combination of location analysis and ESM provides an efficient tool to understand how different work environments, such as cellular office, 
team offices and activity-based offices, are used and how different spaces support task-environment fit. One important limitation in using the ESM is the time used for reporting the event. Although our ESM inquiry involved the steps collecting information on location and participants, combining simultaneous data collection of location of multiple participants would decrease the steps of ESM inquiries.

\section{AKNOWLEDGEMENTS}

This work is funded by European Regional Development Fund A71443 InnoStaVa, and partially by The Finnish Cultural Foundation, and The Academy of Finland projects 314597 ActiveWorkSpace and 3189276Genesis Flagship. Aale Luusua, Arttu Mykkänen ja Henrika Pihlajaniemi are acknowledged for their contribution in designing the pre-analysis phase of the study and ESM questionnaire.

\section{REFERENCES}

Appel-Meulenbroek, R, Groenen, P and Janssen, I 2011, 'An end-user', Journal of Corporate Real Estate, 13(2), pp. 122-135

De Been, I and Beijer, M 2014, 'The influence of office type on satisfaction and perceived productivity support.', Journal of Facilities Management, 12(2), pp. 142-157

van Berkel, N, Ferreira, D and Kostakos, V 2018, 'The experience sampling method on mobile devices.', $A C M$ Computing Surveys (CSUR), 50(6), p. 93

Boutellier, R, Ullman, F, Schreiber, J and Naef, R 2008, 'Impact of office layout on communication in a science冈driven business.', R\&d Management, 38(4), pp. 372-391

De Croon, E, Sluiter, J, Kuijer, PP and Frings-Dresen, M 2005, 'The effect of office concepts on worker health and performance: a systematic review of the literature., Ergonomics, 48(2), pp. 119-134

Bodin Danielsson, C and Bodin, L 2008, 'Office type in relation to health, well-being, and job satisfaction among employees.', Environment and Behavior, 40(5), pp. 636-668

Bodin Danielsson, C, Chungkham, HS, Wulff, $\mathrm{C}$ and Westerlund, H 2014, 'Office design', Ergonomics, 57(2), pp. 139-147

Duffy, F and Powell, K 1997, The New Office, Conran Octopus Limited
Gerdenitsch, C, Korunka, C and Hertel, G 2018, 'Need-supply fit in an activity-based flexible office: a longitudinal study during relocation., Environment and Behavior, 50(3), pp. 273-297

Hartog, L, Weijs-Perrée, M and Appel-Meulenbroek, R 2018 , 'The influence of personality on user satisfaction: multi-tenant offices.', Building Research \& Information, 46(4), pp. 402-416

Heerwagen, JH, Kampschroer, K, Powell, KM and Loftness, V 2004, 'Collaborative knowledge work environments', Building Research \& Information, 32(6), pp. 510-528

Hoendervanger, JG, De Been, I, Van Yperen, NW, Mobach, MP and Albers, CJ 2016, 'Flexibility in use: Switching behaviour and satisfaction in activitybased work environments.', Journal of Corporate Real Estate, 18(1), pp. 48-62

Hoendervanger, JG, Ernst, AF, Albers, CJ, Mobach, MP and Van Yperen, NW 2018, 'Individual differences in satisfaction with activity-based work environments.', PLOSONE, 13(3), p. e0193878

Larson, R and Csikszentmihalyi, M 1983, 'The Experience Sampling Method', in -, - (eds) 1983, New Directions for Methodology of Social \& Behavioral Science, Jossey-Bass

Markkanen, PMH and Herneoja, AM 2018 'Impact of design challenges created by the users of knowledge work environments', Proceedings of the 3rd ARENA Annual Conference, Impact by Designing, Brussels, pp. 51-60

Markkanen, P, Pihlajaniemi, H and Herneoja, A 2017 'Adaptive Lighting for Knowledge Work Environments - A Pilot Design', Proceedings of the 35th International Conference on Education and Research in Computer Aided Architectural Design in Europe, Rome, pp. 343-352

Raento, M, Oulasvirta, A and Eagle, N 2009, 'Smartphones: An emerging tool for social scientists.', Sociological methods \& research, 37(3), pp. 426-454

Van der Voordt, TJ 2004, 'Productivity and employee satisfaction in flexible workplaces.', Journal of Corporate Real Estate, 6(2), pp. 133-148

Weijs-Perrée, M, Appel-Meulenbroek, R and Arentze, T 2018 'Analysing knowledge sharing behaviour in business centres: A Mixed Multinomial Logit Model', TWR 2018 Transdiciplinary Workplace Research conference, Tampere, Finland, pp. 41-61

Wohlers, C and Hertel, G 2017, 'Choosing where to work at work-towards a theoretical model of benefits and risks of activity-based flexible offices.', Ergonomics, 60(4), pp. 467-486 